\title{
Using Innovative Control in Distance Learning of Mining Students to Foreign Languages in the Context of Pandemic
}

\author{
Sergey Lebedintsev ${ }^{1 *}$, Lyubov Fedyanina ${ }^{2}$, and Vyacheslav Gustov ${ }^{1}$ \\ 1. T.F. Gorbachev Kuzbass State Technical University, 650000, 28 Vesennyaya St., Kemerovo, Russia \\ 2. Kemerovo State University, 650043, 6 Krasnaya St., Kemerovo, Russia
}

\begin{abstract}
This article presents innovative control methods used in the online foreign language learning of mining students of a technical university in forced conditions caused by the global pandemic which has been provoked by the coronavirus. The authors of this article substantiate the important role of intermediate control, give a detailed description of its functional tasks and note its intermediary mission by which feedback between a teacher and a student is created which is a necessary factor for the successful formation of language competence as an integral part of professional foreign-language communicative competence in distance learning. The authors of the article have developed a whole range of innovative items in the form of faceted testtables which are successfully used in foreign-language distance learning of mining students in the context of a pandemic.
\end{abstract}

\section{Introduction}

Global changes have been taking place around the world since 2020 . They were caused by a pandemic that had been provoked by a deadly virus that continues to conquer more and more territories of our planet. Self-isolation of citizens, a mask regime, a distance of 1.5 meters, remote work and learning - these are words that have become familiar and firmly embedded in our everyday life. Both the world community as a whole and each country individually are looking for ways to overcome the crisis that has engulfed all spheres of human life.

In the age of new information technologies, digitalization occupies a leading position as the main mechanism for regulating the processes taking place in all segments of modern society. In this connection more than ever before, in our opinion, training of highly qualified personnel in the unforeseen conditions of the humanity existence is becoming relevant and urgent which, thanks to the digital educational environment, will help to find a way out of this situation.

Distance learning is becoming increasingly popular due to two main reasons:

\footnotetext{
* Corresponding author: lebsv1965@mail.ru
} 
Firstly, the global process of digitalization of the population contributes to the change of habitual actions. Now you can not go to the shops, but order everything you need through online services. You can not buy tickets for vehicles in order to be in another country, but simply open a video hosting service and watch the proposed trips in the format of a movie, while refreshing your knowledge of a foreign language and getting acquainted with the customs and traditions of another ethnic group.

Secondly, the use of the Internet in conditions of self-isolation gives you an opportunity for virtual communication between students and teachers which is undoubtedly associated with a rethink of the principles and methods of conventional teaching including foreign language learning.

According to many researchers the use of distance learning in the context of the pandemic allows you to continue the uninterrupted learning process at universities.

\section{Materials and methods}

At present there are scientific works on the stated problems highlighting various innovative approaches to the organization of remote learning, teacher-student's interaction, student's personality development and mastering the competencies proposed to them in the context of a pandemic $[1,2,3]$. These methods are no exception for the organization of distance learning to foreign languages at a technical university. They should be associated, on the one hand, with the use of new advanced innovative technologies, on the other hand, with effective control in foreign language learning.

The term distance learning itself already carries a conceptual load that is directly related to innovative technology. In this article, however, we are going to adhere to the opinion that innovative technologies in education are not only a set of computer programs on electronic media, but also a set of new didactic teaching methods and control techniques used in distance learning to foreign languages. First of all, they should be aimed at improving the professional foreign-language communicative competence of students.

The formation of a professional foreign-language communicative competence is the ultimate goal of mining students' teaching at technical university. In its turn, language competence is one of the main components of communicative competence without which the latter cannot be formed. At the present time language competence is considered not only as knowledge of the language units to be studied at all of its levels (phonetics, vocabulary, grammar, spelling, orthoepy) [4], but also as the ability to use this knowledge and skills in all types of speech activity, which is one of the main conditions for successful completion of the course Foreign Language at the university.

The role and place that language competence plays in the formation of professional foreign-language communicative competence is reflected in the Federal State Educational Standard of Higher Education (FSES HE) for mining specialties as well.

Thus according to requirements of the FSES HE the formation of language competence as an integral element of professional communicative competence is determined by:

- the presence of basic knowledge of the foreign-language speech construction (monologue / dialogue), the correct rule using both in written and in oral communication, the use of knowledge about the norms and structure of the target language;

- the ability to read and translate foreign language texts of general scientific and general professional orientation;

- knowledge of language skills both in oral and in written speech.

All these language skills should form the student's ability to apply the up to date communicative foreign-language technologies both for academic purposes and for professional ones. 
Therefore, for the successful formation of language competence in the context of distance learning, it is necessary to use control that meets all requirements of the pedagogical process because it covers all phases and stages of students' foreign-language learning.

It is known that the final control which task is to diagnose and evaluate the results of students' learning does not fully guarantee the success of their learning goals, since the final positive result of learning in any type of speech activity will completely depend on the intermediate learning goals which can be achieved only with effective means.

It is important for the teacher to have intermediate information about how skills are formed in the four types of speech activity, in order to manage effectively the educational operations of students in foreign language learning. Therefore management in remote foreign-language learning is mainly associated with intermediate control which quality largely determines the final result of the learning activities of subjects taking part in the pedagogical process.

A special feature of the intermediate control as an independent activity is that it doesn't form skills and abilities in foreign language learning by itself, but it establishes a very important feedback between the subjects of the educational process (teacher and student) for the organization of distance learning. The Feedback allows the teacher to evaluate the process of students' learning acquirement about teaching material, a quality of the language competence formation, an application of the knowledge gained to solve practical problems and make the necessary adjustments to the organization of the educational process on the basis of data received. This type of control is primarily aimed at the regular and objective identification of the acquirement level of students, their step-by-step mastering of teaching material in distance learning to foreign languages.

On the other hand, intermediate control has a positive psycho-emotional impact on students in the process of managing their educational and cognitive activities because its influence has a beneficial effect on their attitude to learning. In addition intermediate control is a powerful incentive in the educational process of students in the context of distance learning, which develops volitional qualities, trains them to a certain rhythm that is it disciplines students in foreign language learning.

The success of foreign language teaching in distance learning also depends on the teacher himself, on his rational organization of control methods in the teaching and educational process. Well-conducted control gives a teacher an opportunity to determine the necessary level of students' learning at each specific stage of their foreign language competence formation.

The process of foreign-language competence forming in distance learning is characterized by several important functions determined by a number of pedagogical tasks. These tasks can be traced the analysis of functions that are implemented during the intermediate control. In distance learning the main functional tasks of intermediate control include the following functions, namely: training, diagnostic, corrective, evaluative and educational, motivational and stimulating functions. If we consider them briefly, we can distinguish the following:

The training function of intermediate control is successfully used in control tasks and test items to check a formation of skills and abilities of language competence and operations aimed at the formation of professional communicative competence. The strength and thoroughness of mastering a teaching material, where a student approaches the task performances with maximum responsibility in foreign-language learning, is ensured by mobilizing an intellectual, emotional, and volitional activity of the student himself. The training function, especially in distance learning, contributes to a formation of such a type of control as a student's self-control. 
The diagnostic function of intermediate control which operates throughout the entire distance learning process is primarily related to the training outcomes, to some reasons which a student either mastered or did not master the teaching material.

The corrective function guarantees a validity of intermediate control methods that are used for the object being checked. The main task of this function is to check a level of given students' competence to perform correct speech or language actions during which the teacher can correct incoming information about the object being checked if it is incorrectly perceived by students [5].

The evaluative and educational function of intermediate control is aimed at subjects of the teaching process. While forming speech habits this function evaluates the student's activity from two sides. Firstly, it is aimed at evaluating activities in distance learning to foreign languages. Secondly, it is aimed at assessing the level of a language competence formation. A quality assessment of the student's activity is also of great importance for the teacher. Analyzing the student's learning activities the teacher at the same time evaluates his own activities for the correct organization of learning process and in case of need he can correct it by himself.

The motivational and stimulating function of intermediate control is primarily aimed at maintaining a student's interest in learning and at satisfying the achieved results in his learning activity. In spite of a distance between two subjects in distance learning a very important role plays a verbal (in online classes) or written encouragement of a student by a teacher here. Performing this function the control creates a favorable atmosphere for learning and a positive emotional mood. It also gives each student an opportunity to feel a joy of the academic success that he has achieved in learning process thanks to stimulating role of intermediate control as well as to realize prospects of his successful actions for mastering a foreign language in the context of distance learning.

We should mention another type of control; it is a student's self-control. Self-control as a special type of control plays a very important role in distance learning of students to foreign languages as it mobilizes their organizational skills for effective self-learning. All of the above-mentioned functions of intermediate control are also referred to self-control, however, to a greater or lesser extent.

\section{Results and discussion}

According to the Common European Framework of Reference for Languages [6], each school graduate must be able to use a foreign language communicative competence at or close to the B1 level when entering a higher educational establishment. However, as shown by the long-term results of initial testing in foreign languages (English, German and French) conducted at KuzSTU, the number of students enrolled in mining specialties and being proficient in level $\mathrm{B} 1$ is $10 \%$, the remaining students are proficient in the following levels: A1 - 20\%, A1-A2 - 50\%, A2-B1 - 20\%. One of the reasons for such a low level of communicative competence formation among the former senior pupils, in our opinion, is that the process of foreign language learning at school and the accompanying control were not organized at the proper level.

It follows from this that the formation of language competence at Bachelors of Science in Mining Engineering at the initial stage of learning at the university should be one of the main priorities of high-quality training in foreign languages including distance learning. However, it should be noted that the formation of language competence in the context of distance learning should act not only as an object of study, but also as a means to improve professional communicative competence. Therefore foreign language teachers have a great responsibility for the quality of students' training in foreign language learning. 
To achieve this goal in the context of distance learning a teacher must rely not only on traditional teaching methods in his practical activities but also on innovative technologies and his accompanying methods of intermediate control, a development and an application of which make the learning process the most effective and high-quality.

We agree with the opinion of many methodologists who believe that the modular principle of presenting educational material should be applied as the best method of obtaining knowledge and developing skills in the process of foreign-language distance learning.

The modular principle of distance learning includes three blocks in the process of intermediate control: 1) the theoretical block in which the theoretical language material is presented; 2) the self-control block in which the formation of the student's language skills takes place; 3 ) the intermediate control block in which the level of formation of language skills is checked.

1) The theoretical block which implies a presentation of theoretical language material is mainly associated with a primary consolidation of phonetic units as well as lexical and grammatical structures. This stage forms a theoretical basis of the students' language competence.

2) The self-control block means an application of theoretical knowledge in practice by performing a variety of control tasks and test items to consolidate and improve one or another skill in the module.

3) The intermediate control block determines the level of a language competence formation, a quality of assessment from the results obtained, how well the student has mastered the language material of the module. Performance of the considered error-free automatic actions is an indicator of the student's skill formation. This block is intended for using control tasks and test items at the final stage of work in the module.

As observations show, in the practice of foreign-language distance learning in the context of intermediate control, traditional closed-form test items are mainly used due to their simplicity of construction and quick calculation of the results of responses, the total amount of which can reach $75-100 \%$ in the test. However, these forms of test items do not always meet the requirements of control especially in the context of distance learning, namely:

1) Its objectivity as for results of checking and evaluating students' knowledge as they make it possible to copy off and guess the correct responses at random;

2) Its reliability which implies obtaining non-random but regular test results.

To solve this problem we propose to use a technology of faceted tests [7,8] in faceted test-tables which can be used quite effectively for the formation of language competence in distance learning.

In developing faceted test-tables as well as any faceted test, the principle of variability of test item content is applied "which allows you to create several variants of tasks in one test item, i.e., individual items are combined into one so that the responses of most students are different, that is, the tasks and responses are different, and the topic being tested is the same. Thus the variability of the content of each test item eliminates the possibility of copying off and random guessing of the correct response, thereby contributing to an objective assessment of the results of the completed tasks by students" [9, 4].

If you need to cover a larger number of students with a simultaneous increase in the number of items in this test consisting for example of 15 test items, you will need the following algorithm for composing the test in order to implement this requirement.

The algorithm for creating a test by a teacher in distance learning will include the following steps:

1. You should compile a faceted test-table to check the formation of a certain didactic unit of knowledge. 
2. You should explain the necessary conditions for the test performance by students.

3. You should compile a summary table with the numbers of test items (for example: 1, 2, 3 , etc.) which include facet elements.

Having found his own variant with attached numbers of test items a student proceeds to the summary table, searches for test item numbers with necessary facet elements and begins to perform the test items.

4. Ready to use this faceted test-table, the summary table, the table with a students' list and variants with numbers of test items assigned to each student are attached by a teacher to the group site in the electronic system such as Moodle.

It should be noted that the use of faceted test-tables is characterized on the one hand, by less time spent on the item performance, on the other hand, by the greatest number of individual responses that students give during the distance lesson.

\section{Conclusion}

In conclusion the following should be mentioned that in the course of many years of work on foreign languages at the technical university, we have developed our own system of intermediate control over the formation of the language competence of mining students which is proposed in this article and, in our opinion, is promising at the initial stage of foreign language training at the technical university:

1. The qualitative formation of language competence among mining students in distance learning in the context of the pandemic period is due to the use of a modular system for submitting teaching material.

2. Nowadays the development and application of innovative methods such as faceted testtables in intermediate control and self-control over the formation of mining students' language competence contribute to the most effective and qualitative formation of their professional foreign-language communicative competence in distance learning.

3. In distance learning the use of faceted test-tables, in our opinion, meets the basic requirements of intermediate control over the formation of students' language competence, its objectivity and validity and to a great extent wins towards traditional forms of test items because it significantly minimizes the problem of random guessing or copying off responses by students in the process of intermediate control.

4. Innovative technology of faceted test-tables developed by authors' of this article can be used not only for English teaching, but also for teaching other foreign languages.

\section{References}

1. Guidelines on Distance Education during COVID-19 (Commonwealth of Learning, Burnaby, 2020)

2. E. Rudenko, R. Bachieva, A. Aligadzhieva, Z. Temirhanova, A. Archilaeva, E3S Web Conf. 210, 18038 (2020)

3. I. Pevneva, P. Edmunds, E3S Web Conf. 174, 04001 (2020)

4. W. Hutmacher, Key Competencies for Europe (CDCC, Berne, 1997)

5. S. Lebedintsev, L. Fedyanina, V. Gustov, E3S Web Conf. 174, 04016 (2020)

6. Common European Framework of Reference for Languages: Learning, Teaching, Assessment (Language Policy Unit, Strasbourg, 2001)

7. M. Rahimi, The Reading Matrix, 7:1, 151-165 (2007)

8. H.Sh. Ahmadi, Y. Ozek, E. Demirel, English Language and Literature Studies, 2:2, 11 19 (2012) 
9. S. Lebedintsev, L. Fedyanina, V. Gustov, E3S Web Conf. 105, 04005 (2019) 